\section{Differentiating Asthma from its mimics}

\author{
Zeeshan Waheed, ${ }^{1}$ Muhammad Irfan, ${ }^{2}$ \\ Mohammad Salih, ${ }^{3}$ \\ Ali Bin Sarwar Zubairi²
}

\author{
'Department of Medicine, Armed Forces \\ Hospital Southern Region, Khamis \\ Mushayt, Kingdom of Saudi Arabia; \\ 2Section of Pulmonary and Critical Care \\ Medicine, The Aga Khan University \\ Hospital, Karachi, Pakistan; \\ ${ }^{3}$ Section of Gastroenterology, The Aga \\ Khan University Hospital, Karachi, \\ Pakistan
}

\begin{abstract}
All that wheezes is not asthma this adage accredited to Chevalier Jackson emphasizes the importance of differentiating asthma from its mimics, particularly if the patient is not responding to usual therapy. The above statement also warrants further diagnostic evaluation and management of non-asthma conditions that mimic asthma. We present here a case of a middle aged female who presented with severe bronchospasm, initially labeled as asthma but was resistant to usual anti-asthma therapy. After further workup she was eventually diagnosed to have esophageal achalasia.
\end{abstract}

\section{Introduction}

All that wheezes is not asthma this adage accredited to Chevalier Jackson ${ }^{1}$ emphasize the importance of differentiating asthma from its mimics, particularly if the patient is not responding to the usual anti-asthma therapy. This statement warrants further diagnostic evaluation and management of non-asthma conditions that mimic asthma. ${ }^{2}$ We present here a case of refractory bronchospasm who was resistant to conventional anti-asthma therapy.

\section{Case Report}

This is a 51-year-old lady who presented in emergency department with a history of cough for 15 days, fever for 5 days and progressive shortness of breath for 3 days prior to admission. Her cough worsened after meals and on lying down. Fever was high grade and associated with chills. Shortness of breath was aggra- vated on lying down as well as on mild to moderate exertion. She had a history of recurrent cough for the last 1-2 month associated with shortness of breath prior to coming to our hospital. For this recurrent cough and shortness of breath she had been diagnosed with asthma and was given usual anti-asthma treatment with bronchodilators. Her past medical history was significant for hyperthyroidism, which was treated with Carbamizole for three weeks. She also had symptoms of GERD (Gastroesophageal reflux disease) including heartburn, regurgitation of meal and water-brash for 3 month and had been empirically treated for Helicobacter -pylori induced gastritis. At presentation she was in respiratory distress using her accessory muscles with respiratory rate of 28 breaths per minute. Her chest examination revealed bilateral diffuse poly-phonic rhonchi and crackles at the bases. Chest X-ray was normal. She was admitted to the Pulmonary service with a working diagnosis of infective exacerbation of asthma and was initially treated with intravenous corticosteroids, nebulizers and antibiotics. The next morning she was feeling symptomatically better but her physical examination revealed significant stridor, and chest auscultation revealed conducting sound from the upper airways. An upper airway obstruction was suspected. She underwent bedside spirometry with flow-volume loop, which did not revealed any signs of upper airway obstruction. Computed tomography scan of Neck and Chest revealed a dilated cervical and thoracic esophagus with food particles, causing compression and anterior displacement of the trachea (Figure 1) Barium Swallow was done which showed dilated esophagus with acute tapering producing a typical Bird's beak appearance, highly suggestive of esophageal achalasia (Figure 2) She underwent endoscopic balloon dilatation of the lower esophageal sphincter, she started to improve immediately after the procedure and was discharged home the next day. On routine follow-up at 3 month she was completely symptoms free.

\section{Discussion}

There are variety of conditions/diseases that can present as asthma like symptoms mainly bronchospasm and wheezing, These conditions include chronic obstructive pulmonary disease (COPD), congestive heart failure (CHF), primary endobronchial tumors e.g. bronchial carcinoid tumors, endobronchial metastases (e.g. from breast carcinoma), pulmonary embolism, cystic fibrosis, bronchiectasis, hypersensitivity pneumonitis, aspiration syndromes, foreign body aspiration, vocal cord dysfunction, bronchomalacia, tracheal steno-
Correspondence: Zeeshan Waheed, Department of Medicine, Armed Forces Hospital Southern Region (AFHSR), P.O.Box 101, Khamis Mushayt, Kingdom of Saudi Arabia.

Tel. +966.7250001 Ext: 22531; Mobile: +966 . 537245082. E-mail: szwaheed@gmail.com

Key words: asthma, bronchspasm, esophageal achalasia.

Received for publication: 28 August 2011.

Revision received: 20 0ctober 2011.

Accepted for publication: 25 October 2011.

This work is licensed under a Creative Commons Attribution NonCommercial 3.0 License (CC BYNC 3.0).

(C) Copyright Z. Waheed et al., 2011

Licensee PAGEPress, Italy

Chest Disease Reports 2011; 1:e17

doi:10.4081/cdr.2011.e17

sis, and tracheal compression from mediastinal masses. ${ }^{3}$ All these conditions should be kept in mind when dealing with patients who present with wheezing and bronchspasm especially in those who do not respond to the usual anti-asthma treatments. Respiratory complications from esophageal achalasia have been described previously in the literature..$^{4-10}$ These respiratory complications occur from the recurrent regurgitation of meals and from

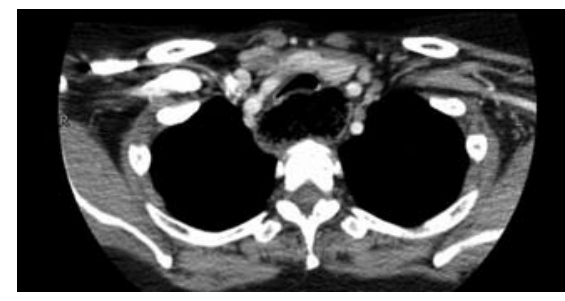

Figure 1. Computed tomographic scan of the chest.

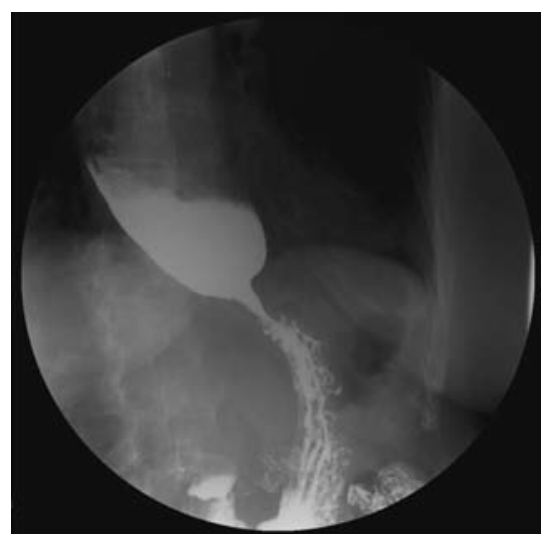

Figure 2. Barium Swallow of the patient. 
direct compression of airways by a dilated esophagus. This results in recurrent aspiration pneumonia, lung abscesses formation, recurrent cough especially after meals, significant bronchospasm/wheezing, respiratory distress and very rarely acute stridor.-10 Our patient presented with severe bronchospasm because of tracheal compression and also from aspiration of gastric contents. Diagnoses of asthma mimics are particularly important to consider when the presentation is atypical for asthma e.g. age at onset, negative family history, timing of symptoms and especially when the response to usual anti-asthma treatment is suboptimal or the patient presents with refractory/resistant bronchospasm) or there is some evidence of alternative diagnosis on imaging like mediastinal widening on chest X-ray. The scenario can be more complex when asthma mimics co-exist with actual asthma. ${ }^{3}$

\section{Conclusions}

A high index of suspicion is required for diseases that mimic asthma, particularly when the patient fails to respond to anti-asthma therapy.

\section{References}

1. Robbins JJ. Wheezing and bronchial asthma. Calif Med 1970;113:88-9.

2. Low SY, Eng P. All that wheezes is not asthma-broncholithiasis, a forgotten disease. Ann Acad Med Singapore 2002;31:528-30.

3. King CS, Moores LK. Clinical asthma syndromes and important asthma mimics. Respir Care 2008;53:568-80.

4. Bello CT, Lewin JR, Norris CM, Farrar GE Jr. Achalasia (cardiospasm): report of a case with extreme and unusual manifestations. Ann Intern Med 1950;32:1184-90.

5. Dunlop SP, Travis SP. Achalasia presenting as acute stridor. Eur $\mathrm{J}$ Gastroenterol Hepatol 1997;9:1125-8.

6. Arcos E, Medina C, Mearin F, et al. Achalasia presenting as acute airway obstruction. Dig Dis Sci 2000;45:2079-83.

7. Mincewicz G, Wasilewska E, Aloszko A, et al. Pseudoasthmatic syndrome due to achalasia cardiae. Pol Merkur Lekarski 2004;17:483-5.

8. Wasilewska E, Mincewicz G, Kurowski W, et al. Pulmonary masks of achalasia cardiae. Wiad Lek 2005;58:557-60.

9. Khan AA, Shah SW, Alam A, et al. Achalasia esophagus; presenting as acute air way obstruction. J Pak Med Assoc 2007;57:4235 .

10. Bacellar P, Silva M, Tinoco N, Costa F. Oesophagus achalasia: differencial diagnosis of asthma. Rev Port Pneumol 2008;14:309-13. 